American J. of Engineering and Applied Sciences 1 (4): 280-286, 2008

ISSN 1941-7020

(C) 2008 Science Publications

\title{
Fuzzy Based Digital Automatic Voltage Regulator of a Synchronous Generator with Unbalanced Loads
}

\author{
A. Darabi, S.A. Soleamani and A. Hassannia \\ Faculty of Electrical and Robotic Engineering, Shahrood University of Technology, \\ Shahrood, Iran
}

\begin{abstract}
Voltage stability and power quality of the electrical systems depend on proper operation of the Automatic Voltage Regulators (AVR) of generators. Nowadays, design technology of the AVRs is being broadly improved. According to wide range operating conditions of the generators and loads, the fuzzy AVRs are going to be the modern type of regulators, particularly, for the genset alternators operating in distribution systems. There are many research presented on the optimum performance of the fuzzy AVRs. They are focused mostly on the balanced loads with minor attention to the unbalanced loads and voltages that are very common for the generating sets embedded in distribution systems. In this study, performances of a simulated digital fuzzy AVR evaluated for a wide range of unbalanced loads operating conditions. Feedback signals, sampling time and scaling factors of fuzzy logic based controller have significant impacts on the overall system performance. A few quality indices are specified and their values are compared for different feedback signals and various unbalanced operating conditions and accordingly, the optimum feedback signal is introduced.
\end{abstract}

Key words: Synchronous generator, voltage regulator, unbalanced load, fuzzy logic

\section{INTRODUCTION}

According to the standards, the voltage profiles should be kept within the certain limits. Since the voltage profile is consistently varied by load fluctuations so it should be controlled permanently by Automatic Voltage Regulator $(\mathrm{AVR})^{[1]}$. For the generators, an increase in reactive power demand yields some decreases in terminal voltage. This voltage reduction is compensated by some increments in the field current and generating more reactive power through AVR and exciter machine.

Controlling the voltage and reactive power by tuning of the main field current of the generators was introduced for the first time in 1960. After that the technologies of the AVRs have been improved greatly. The responding of the old AVRs to error signals is quiet slow and they are not able to be scheduled using a complicated control strategy. In 1970 K. j. Runtz applied the digital AVRs to control the field current of a generator $^{[2]}$. Digital AVRs are flexible and can employ complex methods such as: nonlinear control, neural network, fuzzy logic, genetic algorithm and etc for reliable performance of whole system in various operating conditions of the generating set and loads.
Prof. Lotfi Zadeh introduced fuzzy logic theory in $1965^{[3]}$. Since then, fuzzy logic theory has been implemented successfully in several applications. Recently, fuzzy logic theory has been used frequently to increase the power capacity, stability and efficiency of the power systems ${ }^{[4]}$. Nowadays, the fuzzy logic is attended in the structure of automatic voltage regulators and some research have discussed various performance optimization methods engaged for these type regulators.

In the present research, a digital fuzzy AVR is simulated in an unbalanced system and its performances are evaluated from different points of view. It is shown that AVR performances are significantly affected by the sampling time, scaling factors and voltage feedbacks. The impacts of these three parameters on the AVR performances are considered here in this study and their optimized values are determined by precise analysis of the simulation results.

Modelling: The system which is developed to study the transient and steady state performance of a fuzzy based digital AVR consists of a local load supplied by a small synchronous generator (31.5KVA) with an automatic voltage regulator shown in Fig. 1. All components of the system are modelled in details.

Corresponding Author: A. Darabi, Faculty of Electrical and Robotic Engineering, Shahrood University of Technology, Shahrood, Iran 


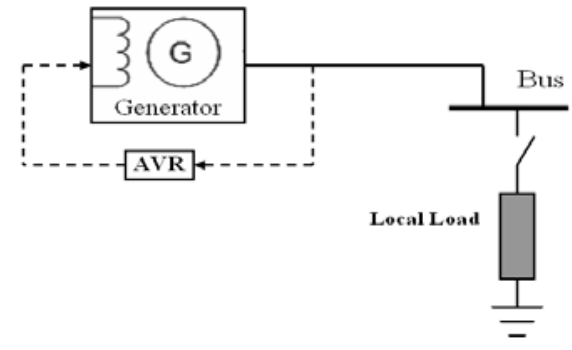

Fig. 1: simulated system

Alternator: Alternator is the main component of the system with a wide range operational zone. The synchronous generator is modelled in the original abc frame using the machine parameters (harmonic content inductances) obtained by a finite elements based simulations ${ }^{[5]}$. These space harmonic content inductances of a concentric asymmetric stator and rotor windings produce a model which predicts machine behaviour most accurately.

Voltage equations of the machine can be written as:

$$
\begin{aligned}
& {[\lambda]=[\mathrm{L}(\theta)][\mathrm{i}]} \\
& {[\mathbf{e}]=\frac{\mathrm{d}[\lambda]}{\mathrm{dt}}}
\end{aligned}
$$

Where:

$$
\begin{aligned}
\lambda= & \text { vector of linkage fluxes } \\
\mathrm{i}= & \text { currents vector and } \\
\mathrm{e}= & \text { represents the induced voltages of the stator } \\
& \text { and rotor windings. }
\end{aligned}
$$

Governor: Frequency oscillations of the generators have great impact on the stable performance of the machine and system. When the generator is connected to the network, the governor controls the input mechanical power, but during island operation when the generator supplies a local load, the governor controls the frequency disregarding the input or output power. However the frequency oscillation and governor response affect the AVR performance during transient states. Figure 2 shows model of the governor used in this study. The parameters of the governor are:

$$
\begin{aligned}
& \mathrm{a}=0.00016, \mathrm{~b}=0.044, \mathrm{c}=1, \mathrm{R}=0.02 \\
& \mathrm{~J}=1, \mathrm{D}=0.01, \mathrm{P}_{\text {base }}=31500, \omega_{\text {base }}=50 \pi
\end{aligned}
$$

" $\mathrm{T}_{\mathrm{e}}$ " shown in Fig. 2 is the electromagnetic torque and is calculated by:

$$
\mathrm{T}_{\mathrm{e}}=\frac{1}{2}[\mathrm{i}]^{\mathrm{T}} \frac{\mathrm{d}[\mathrm{L}(\theta)]}{\mathrm{d} \theta}[\mathrm{i}]
$$

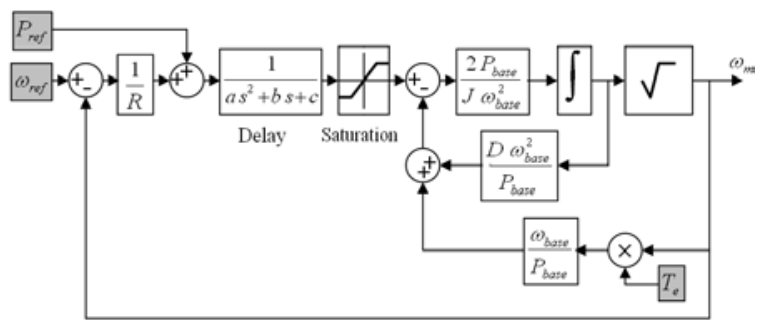

Fig. 2: Speed Control System

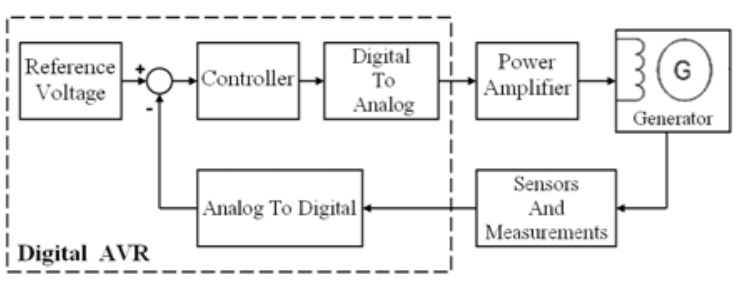

Fig. 3: Digital AVR of a generator

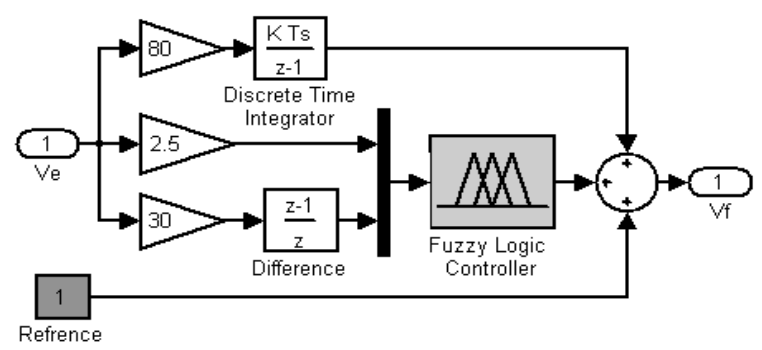

Fig. 4: Digital Fuzzy Controller

Digital fuzzy AVR: The block diagram of whole system including a digital voltage regulator is shown in Fig. $3^{[6]}$. The AVR blocks are implemented digitally using a microprocessor.

The controller block of the AVR used here consists of a fuzzy controller working in parallel with a digital PI controller as shown in Fig. 4. Terminal voltage is mainly settled down by fuzzy controller and to eliminate the steady state error of the terminal voltage a PI controller is employed.

There are two common inference processes for fuzzy controllers ${ }^{[7]}$. First is called Mamdani's fuzzy inference method proposed in 1975 by Ebrahim Mamdani $^{[8]}$ and the other is Takagi-Sugeno-Kang, or simply Sugeno method, Introduced in $1985^{[9]}$. These two methods are similar in many aspects, such as the inputs, the procedure of fuzzification and fuzzy operators. The Mamdani's fuzzy inference method is the one selected for the development of the fuzzy controller, as it provides more flexibility to implement the control strategy down to finest details. This 
Table 1: Definition of fuzzy controller linguistic variables

\begin{tabular}{ll}
\hline Linguistic variables & Definition \\
\hline PVL & Positive Very Large \\
PL & Positive Large \\
PM & Positive Medium \\
PS & Positive Small \\
PVS & Positive Very Small \\
Z & Zero \\
NVS & Negative Very Small \\
NS & Negative Small \\
NM & Negative Medium \\
NL & Negative Large \\
NVL & Negative Very Large \\
\hline
\end{tabular}

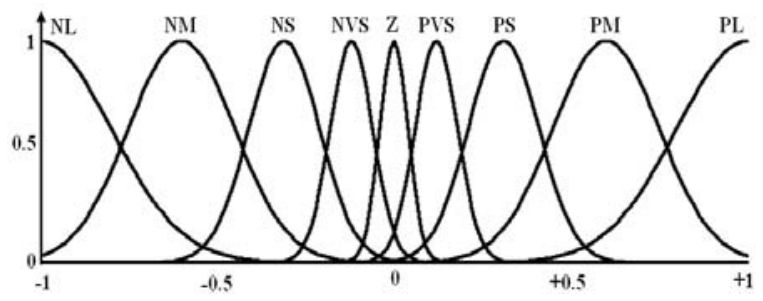

Fig. 5: Membership functions of error signal

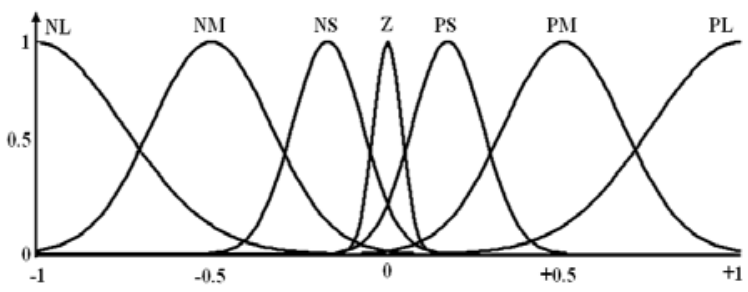

Fig. 6: Membership functions for rate of change of error signal

controller has two input signals, an error signal (e) and its rate of change (de/dt). The linguistic variables of these inputs are defined in Table. 1.

Error signal is the deviation between the set point (desired value that usually equals to $1^{\mathrm{PU}}$ ) and the feedback value. Let us suppose that the error signal and its rate of change vary between -1 to +1 . Rate of change of error signal is applied for quick response of the controller to any rapid and large disturbances. For designing a fuzzy controller, some membership functions are normally specified regarding to the system and experiments. For the error signals and its rate of change the following 9 and 7 Gaussian membership functions are assigned as shown respectively in Fig. 5 and 6.

As shown in Fig. 4, fuzzy controller has only one output signal and we suppose that its value are between $-10-10$. The membership functions of the output signal are 11 Gaussian functions as given in Fig. 7.

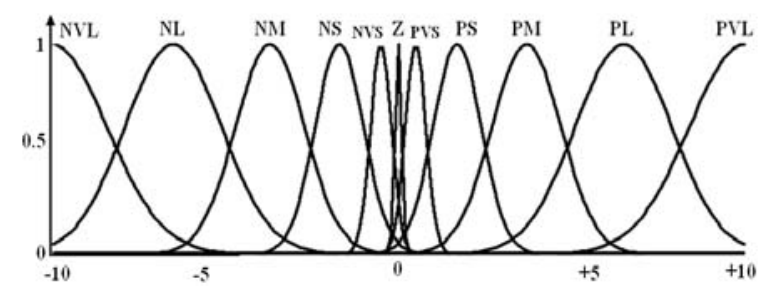

Fig. 7: Membership functions of output signal

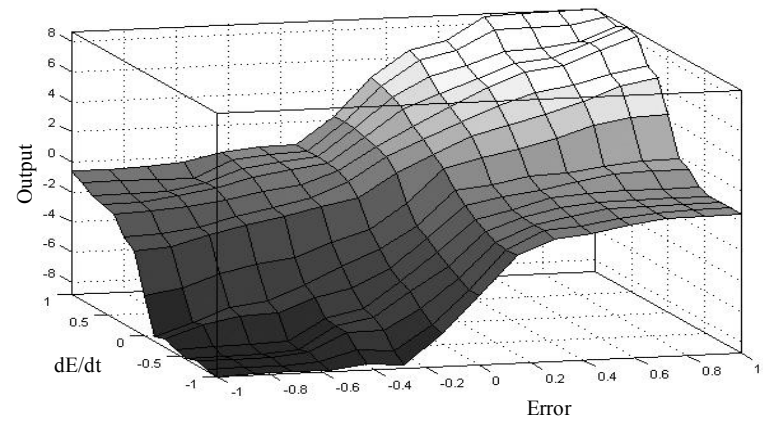

Fig. 8: Resultant surface of the fuzzy rule set

Since the membership functions of two input signals are 9 and 7, so the rule base of fuzzy controller comprises 63 rules. The proposed 63 fuzzy rules as a non-linear rule set surface representing whole controller dynamics are demonstrated graphically in Fig. 8.

\section{Simulation:}

Sample time: The performances of digital systems are affected deeply by sample rate. Sampling with a high frequency of voltage feedback signal leads to a large computations and this require very fast and more expensive microprocessors if available. On the other hand, sampling with low frequency may produce great ripples in the AVR output signal in many circumstances and this rough AVR response affects proper performances of the overall system. For three different sampling times of $0.05,0.001$ and $0.0001^{\mathrm{Sec}}$, the AVR output signals are shown in Fig. 9-11 respectively when the generator is subjected to a step load. The corresponding terminal voltages for three sampling times are shown in Fig. 12 for comparison. The step load used here is a full load with $0.8^{\text {lag }}$ power factor that applied to a no load generator. As can be seen clearly from the Fig. 9 when the sampling time is $0.05^{\mathrm{Sec}}$, the output signal of the AVR contains high frequency components and this yields to a terminal voltage with higher Settling Time (Ts) and Percentage Overshot (PO) value in comparison with the cases of lower sampling times illustrated in Fig. 10. Furthermore by 


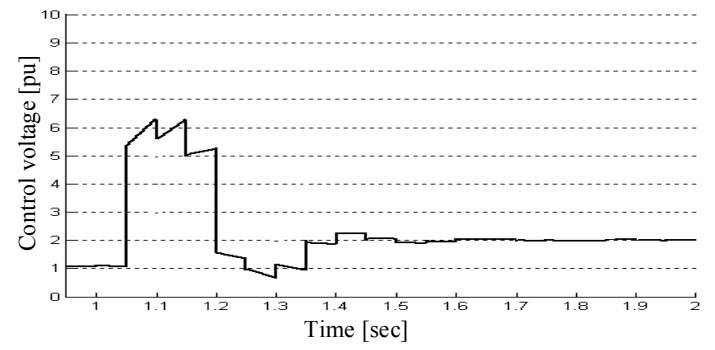

Fig. 9: Output signal of the AVR for sample time $\mathrm{T}=0.05^{\mathrm{Sec}}$

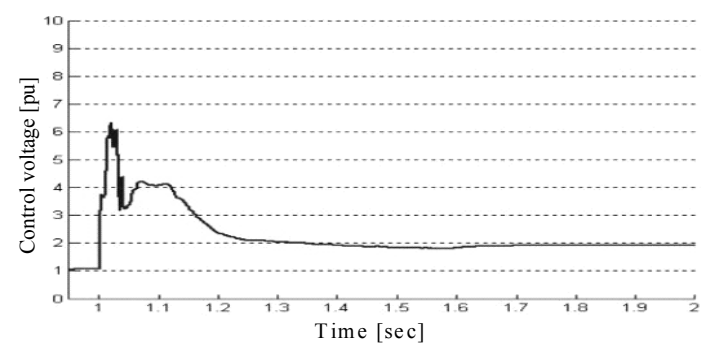

Fig. 10: Output signal of the AVR for sample time $\mathrm{T}=0.001^{\mathrm{Sec}}$

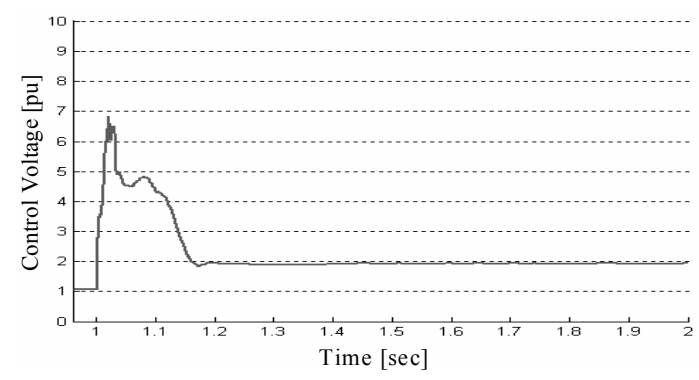

Fig. 11: Output signal of the AVR for sample time $\mathrm{T}=0.0001^{\mathrm{Sec}}$

comparison of the AVR output signals (Fig. 10 and 11) and terminal voltage graphs (Fig. 12) for 0.001 and $0.0001^{\mathrm{Sec}}$ sampling times, when the sampling time is less than $\mathrm{T}=0.001$ seconds, no considerable improvement appears in the AVR and overall system responses. Similar simulation results are achieved for other loads. Therefore, applying any sampling frequencies higher than $1000^{\mathrm{Hz}}$ for a $50^{\mathrm{Hz}}$ terminal voltage would be costly and leads to a time consuming product. Briefly for a $50^{\mathrm{Hz}}$ systems it can be claimed that $\mathrm{T}=0.001^{\mathrm{Sec}}$ is the best value for the sample time of the feedback signal.

Scaling factors: As mentioned earlier, there are two inputs for fuzzy controller, error signal and its rate of

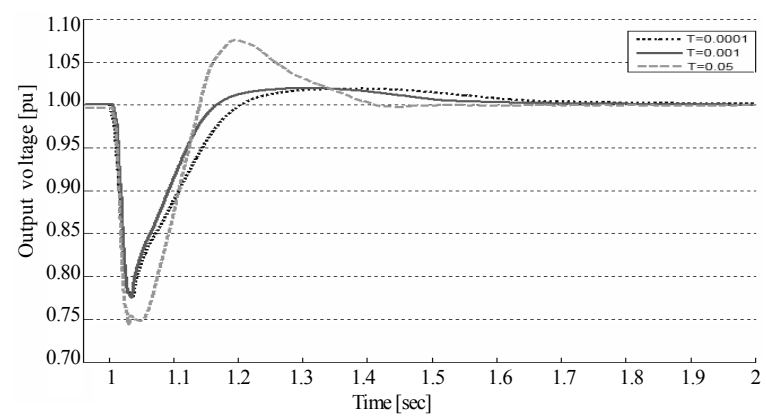

Fig. 12: Terminal voltage variations of the generator with different sample times during step load application

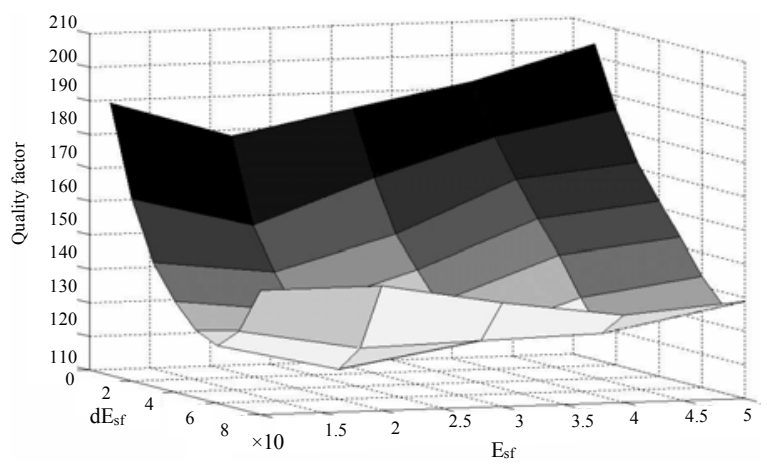

Fig. 13: Variation of quality index versus scaling factors

change. Each of the inputs has a constant gain that presents its weight on control system. Assignment the proper values for these weighting or scaling factors is significant due to their great impact on the AVR performances. For this purpose various simulations are carried out and based on a quality evaluation index, approximate optimum values for them are deduced. The index comprises some important factors of the whole system performance surmised in a linear normalized combination such as:

$$
\mathrm{QF}=\mathrm{PO}+\mathrm{T}_{\mathrm{s}}+\mathrm{AO}_{\text {max }}
$$

where $\mathrm{QF}$ is quality valuation index, $\mathrm{PO}$ is the percentage overshoot of the terminal voltage, Ts is the settling time and $\mathrm{AO}_{\max }$ is the maximum value of the AVR output signal. Variation of quality index versus scaling factors is shown in Fig. 13. The optimum values of the scaling factors are 2.5 and 30 for the error signal $\left(E_{s f}\right)$ and its rate of change $\left(\mathrm{dE}_{\mathrm{sf}}\right)$ respectively as seen in Fig. 13. The scaling factors are mostly depended on the machine parameters and since for the embedded generation units in a distribution system the per-unit 


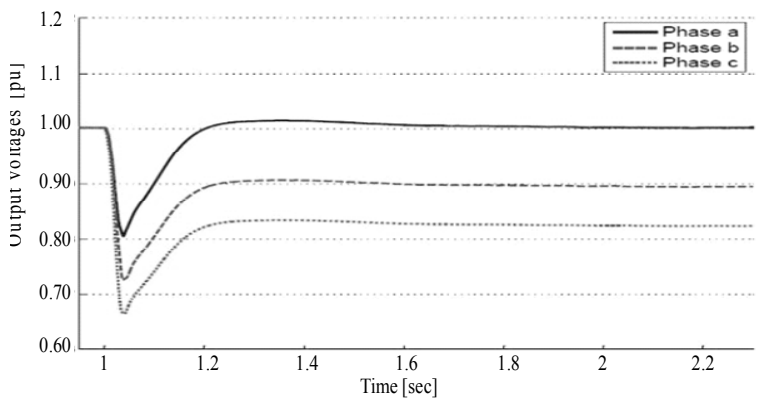

Fig. 14: Voltage recovery during unbalanced step load, when the feedback signal is voltage of phase a

machine parameters do not vary too much, therefore the authors believe these scaling factors with a minor correction can be used for almost all similar machines.

Voltage feedback: The field current, electric power, reactive power and frequency can be used as the feedback signal in the automatic voltage regulator ${ }^{[10]}$. But common feedback signal is the line voltage of the generator. In the lack of harmonics, when a generator is supplying a balanced load, all of the phase or line voltages are the same and one of them can be applied as AVR's feedback signal. On the other hand for the unbalanced loads, normally, phase voltages are not equal and so there is no unique feedback voltage for the AVR. In the unbalanced system, choosing one of the phase or line voltages or a combination of them as a feedback voltage for the AVR can influence the harmonic content, voltage diversity from the mean rms value of three phase voltages and other power quality indices of overall system performance differently. For this consideration many simulations are carried out when different feedbacks are engaged for various balanced and unbalanced step loads applications. For example, if an unbalanced load in the form of $0.25,1$ and $0.8^{\mathrm{PU}}$ at phases $\mathrm{a}, \mathrm{b}$ and $\mathrm{c}$ respectively is switched suddenly to the no-load generator, three phase voltages will dropped differently. Voltage recovery extremely depends on the feedback signal of the AVR. The AVR apart from the values of other phase voltages will adjust the feedback voltage to a predetermined value e.g., $1^{\mathrm{PU}}$. Three phase terminal effective voltages of the generator for aforementioned unbalanced load are shown in Fig. 14-16 when the feedback signal is the effective voltage of phase a, b or c respectively. As seen in Fig. 14-16 one or two steady-state terminal voltages for each figure are adjusted to the values much above or much below the predetermined $1^{\mathrm{PU}}$ after first transient period. Briefly the variances of voltages are rather great for all three feedbacks. If the root-mean-square value of

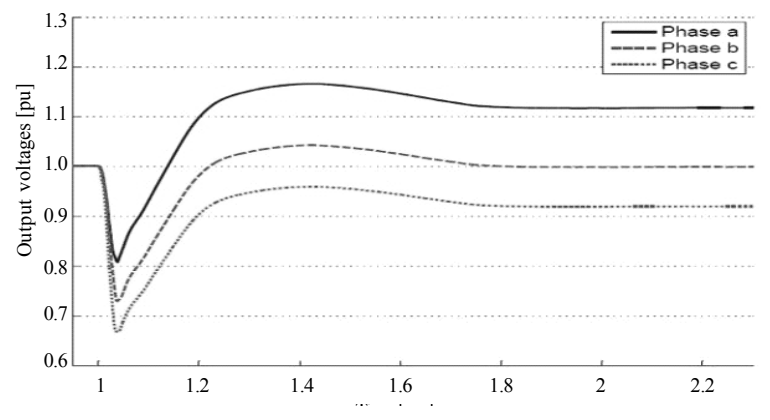

Fig. 15: Voltage recovery during unbalanced step load, when the feedback signal is voltage of phase $b$

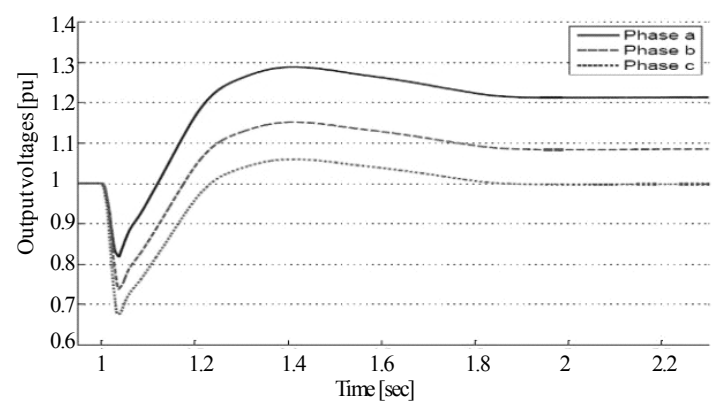

Fig. 16: Voltage recovery during unbalanced step load, when the feedback signal is voltage of phase $\mathrm{c}$

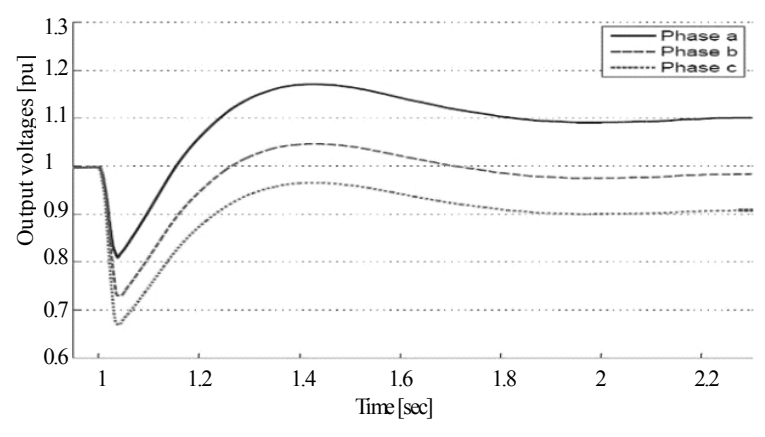

Fig. 17: Effective values of the three phase voltages when the feedback signal is from Root-MeanSquare of phase voltages

the instantaneous voltages of three phases as $\mathrm{v}_{\mathrm{FB}}=\sqrt{\left(\mathrm{v}_{\mathrm{a}}^{2}+\mathrm{v}_{\mathrm{b}}^{2}+\mathrm{v}_{\mathrm{c}}^{2}\right) / 3}$ is used as a feedback signal, variance of rms voltages will decrease significantly. Figure 17 shows the rms voltage variations of three phases when the feedback is root-mean-square of instantaneous three-phase voltages. The variances of three phase voltages for Fig. 14-16 are shown in Fig. 18. As can be seen from this figure the variance for Fig. 17 is the minimum one. 


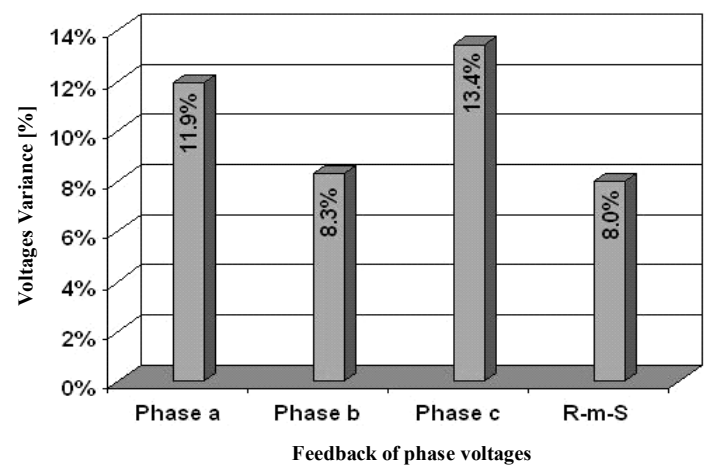

Fig. 18: Three phase voltages variances with different feedbacks

Table 2: Three phase voltages variances with different feedbacks in different loads

\begin{tabular}{lll}
\hline & $\begin{array}{l}\text { Average variance for } \\
\text { feedback from root- } \\
\text { mean-square of the } \\
\text { phase voltages }\end{array}$ & $\begin{array}{l}\text { Average variances } \\
\text { for feedbacks from } \\
\text { phase } \mathrm{a}, \mathrm{b} \text { and } \mathrm{c}\end{array}$ \\
\hline $1-1-1$ & 0 & 0 \\
$0.5-1-1$ & 5.6 & 8 \\
$0.5-0.5-1$ & 6.1 & 8.5 \\
$0.5-0.5-0.5$ & 0 & 0 \\
$0-1-1$ & 12.3 & 17.7 \\
$0-0-1$ & 13.6 & 19.3 \\
$0-0.5-0.5$ & 7.2 & 10.3 \\
$0-0-0.5$ & 7.5 & 10.5 \\
\hline
\end{tabular}

Table 2, presents similar comparison of average variances for a variety of balanced and unbalanced loads when the phase voltages and root mean square of three phase voltages are used as input signals of the AVR.

The problem with feedback from root mean square phase voltages is that the existing time and structural space harmonics produce some harmonics in the terminal voltages and this yield to some ripples in the resultant root mean square voltages. Similar problem is occurred when the generator is subjected to an unbalanced load. In this situation a large backward mmf is produced and cause extreme ripples in the aforementioned feedback signal. Figure 19 shows the feedback voltage during an unbalanced load condition. Error signal is the AVR's input signals that derived directly from this feedback so the AVR performance is affected by these ripples. Furthermore, the ripples have a greater impact on the error signal rate of change, which is applied as another AVR's input signal. Figure 20 shows the rate of change of error signal for an operating condition in which its values vary between two boundaries greater than $1^{\mathrm{PU}}$ and less than $-1^{\mathrm{PU}}$. As already mentioned, for compatibility the membership functions of this signal vary between -1 to +1 .

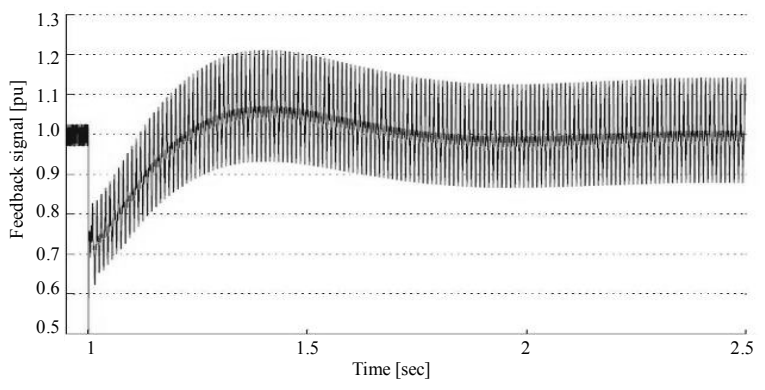

Fig. 19: Root-Mean-Square of phase voltages in unbalanced load

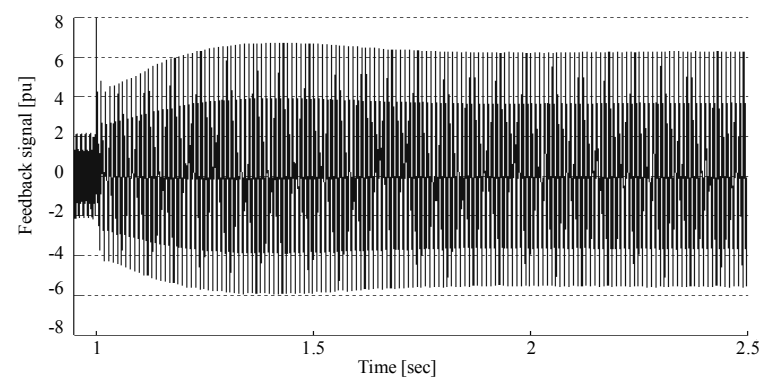

Fig. 20: Error signal rate of change with Root-MeanSquare of the phase voltages feedback

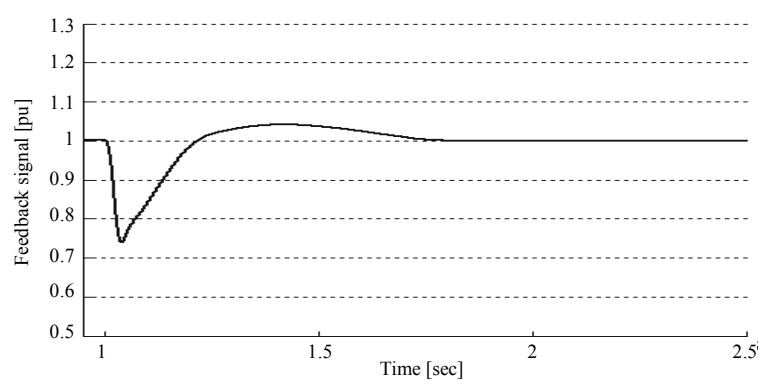

Fig. 21: Average rms values of phase voltages in unbalanced load

Therefore the fuzzy controller will ignored the exceeding values and this will affect badly the AVR and overall system performances. To overcome this problem, the average rms values of phase voltages can be used instead as the feedback signal. If the average rms value of the phase voltages is applied as the feedback a typical signal with no visible ripple will be as shown in Fig. 21. This signal similar to root mean square value of the phase voltages yields to minimum variance phase voltages for unbalance load applications. Furthermore for this feedback the rate of change of error signal reminds within desired margin and provides full details including rapid change of error 
Am. J. Engg. \& Applied Sci., 1 (4): 280-286, 2008

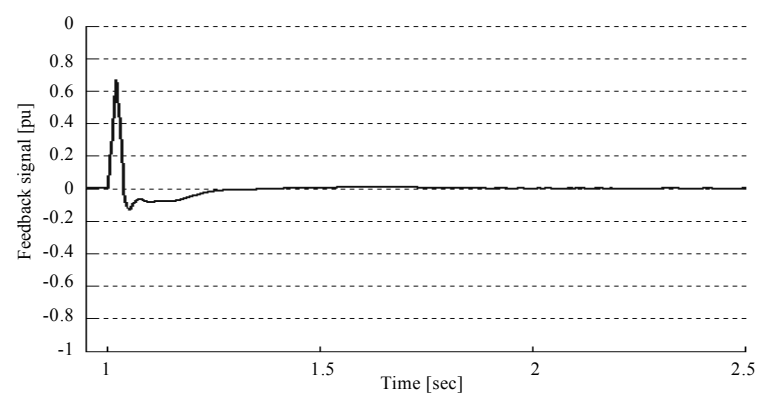

Fig. 22: Error signal rate of change with average rms values of the phase voltages feedback

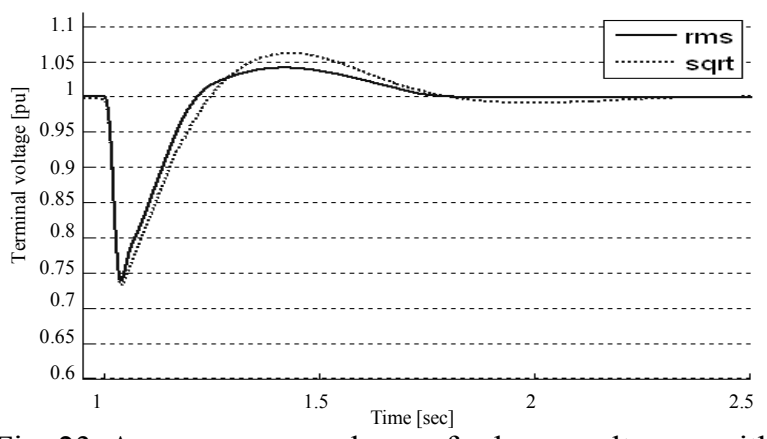

Fig. 23: Average rms values of phase voltages with different feedbacks during an unbalanced load switching

signal as shown in Fig. 22. As mentioned There is no great ripples in the AVR's input signals especially in the rate of change of error signal as shown typical signals in the Fig. 21 and 22 respectively for unbalance load. As an example, average of rms terminal voltages with two different feedback signals, 1-root mean square and 2-average rms itself, for an unbalanced load are shown in Fig. 23 for comparison. The figure shows that the AVR with average rms feedback in comparison with root mean square feedback provides a better performance regarding the $\mathrm{PO}, \mathrm{Tr}$ and Ts responses of the terminal voltage with no extra cost.

\section{CONCLUSION}

In this research, the simulation results of a digital fuzzy based AVR of a synchronous generator in balanced and unbalanced load operating conditions are presented. Simulation results for a $50 \mathrm{~Hz}$ network approve that the optimum sampling time for a digital AVR is about $T=0.001^{\mathrm{Sec}}$. The ripples of AVR output signal and performance of overall system are improved by this cost effective sampling rate. Moreover, by a variety of simulations, the optimum values of scaling factors for the input signals of the fuzzy controller are determined. The associated gains for voltage error and its rate of change are 2.5 and 30 respectively. These values can be applied for similar AVRs hired in distribution networks for embedded generators. Performance evaluations of the characterized digital AVR in unbalanced load operation demonstrate that the voltage feedback has a major contribution in voltage variance. It is shown that instantaneous root mean square of three phase voltages and average rms value of the phase voltages yield minimum voltage variance. Furthermore, comparing with feedback from rootmean-square of instantaneous phase voltages, the average of rms values of phase voltages provides smaller ripples and better characteristics of overall system responses.

\section{REFERENCES}

1. Mendoza, J.E., Morales D.A., López R.A., López E.A., Vannier J.C., Coello Coello C.A., 2007. Multiobjective location of automatic voltage regulators in a radial distribution network using a micro genetic algorithm. IEEE Trans. Power Syst., 22 (1), pp: 404-412, DOI: 10.1109/TPWRS.2006.887963.

2. Runtz, K.J., Farag A.S.A., Huber D.W., Hope G.S., Malik O.P., 1973. Digital control scheme for a generating unit. IEEE Trans. PAS, 92 (2), pp:478483, DOI: 10.1109/TPAS.1973.293747.

3. Zadeh, L.A., 1965. Fuzzy Sets. Inform. Control, 8, pp: 338-353.

4. Kannan, S., Jayaram S., Salama M.M.A., 1998. Fuzzy logic based supplementary controller for static synchronous series compensator. IEEE Canadian Conference on Electrical and Computer Engineering, 2, pp: 489-492, DOI: 10.1109/CCECE.1998.685540.

5. Darabi, A, 2005. Auxiliary windings, supplying the AVR of a brushless synchronous generator. Proceedings of the Eighth International Conference on Electrical Machines and Systems (ICEMS), 1, 27-29 sept. 2005, pp: 81-85.

6. IEEE Digital Excitation App, Task Force of Excitation Systems Subcommittee, 1997. Digital excitation technology - a review of features, functions and benefits. IEEE Trans. On Energy Con., 12 (3), pp: 255-258, DOI: 10.1109/60.629711.

7. Wang, L., 1996. A Course in Fuzzy Systems and Control. Prentice Hall, Paperback, 1.

8. Mamdani, E., Assilian S., 1975. An experiment in linguistic synthesis with a fuzzy logic controller. Int. J. Man-Mach. Stud., 7, pp: 1-13.

9. Sugeno, M., 1985. Industrial Applications of Fuzzy Control. Elsevier Science Inc, New York, NY.

10. Eberhart, R.C, Shi Y., 1998. Comparison between Genetic Algorithms and Particle Swarm Optimization. Springer-Verlag, London, UK., pp: 611-616. 